\title{
Atividade antimicrobiana, antiaderente e antifúngica in vitro de plantas medicinais brasileiras sobre microrganismos do biofilme dental e cepas do gênero Candida
}

\author{
In vitro antimicrobial, antiadherent and antifungal activity of Brazilian \\ medicinal plants on oral biofilm microorganisms \\ and strains of the genus Candida
}

\author{
Pollianna Muniz Alves ${ }^{1}$, Lélia Maria Guedes Queiroz ${ }^{2}$, Jozinete Vieira Pereira ${ }^{3}$ \\ e Maria do Socorro Vieira Pereira ${ }^{4}$
}

\begin{abstract}
RESUMO
Avaliou-se in vitro a atividade antimicrobiana, antifúngica e antiaderente da aroeira-do-sertão, malva e goiabeira sobre microrganismos do biofilme dental e candidose oral. Os extratos mostraram-se eficazes, inibindo o crescimento das bactérias do biofilme dental e fungos da candidose oral, sugerindo a utilização dessas plantas como meio alternativo na terapêutica odontológica.
\end{abstract}

Palavras-chaves: Biofilme dental. Plantas medicinais. Streptococcus. Lactobacillus. Candida.

\begin{abstract}
The antimicrobial, antifungal and antiadherent activity of aroeira-do-sertão, mallow and guava tree on oral biofilm microorganisms and oral candidiasis was evaluated in vitro. The extracts were shown to be effective in inhibiting the growth of bacteria of the oral biofilm and fungi of oral candidiasis, thus suggesting that these extracts can be used as alternative means of dental therapy.
\end{abstract}

Key-words: Oral biofilm. Medicinal Plants. Streptococcus. Lactobacillus. Candida.

O biofilme dental é o fator de maior importância na etiologia da cárie e das doenças periodontais, e há uma relação muito grande com a higiene bucal deficiente ${ }^{8}$. A remoção mecânica constitui o método mais aceito para o seu controle, mas o uso de coadjuvantes químicos é bastante valioso $0^{6}$. A candidose bucal é uma infecção causada pela levedura do gênero Candida, a qual é um microrganismo saprófito, que, na dependência de fatores predisponentes, torna-se patogênic $0^{9}$. Vários agentes antifúngicos são utilizados em seu tratamento, como também a clorexidina, mas devido os efeitos colaterais decorrentes do uso prolongado, a sua utilização permanece restrita ${ }^{7}$.

Diversos produtos de origem vegetal mostram ser potencialmente interessante, no que se refere a sua atividade antimicrobiana ${ }^{12}$. Dentre estas se destacam a malva, a aroeira e a goiabeira. A malva (Malva

\footnotetext{
1. Programa de Pós-graduação em Patologia Oral, Universidade Federal do Rio Grande do Norte, Natal, RN. 2. Departamento de Odontologia, Universidade Estadual da Paraíba, Campina Grande, PB. 3. Programa de Pós-Graduação em Odontologia, Universidade Federal da Paraíba, João Pessoa, PB. 4. Departamento de Biologia Molecular. Centro de Ciencias Exatas e da Natureza, Universidade Federal da Paraíba, João Pessoa, PB.

Endereço para correspondência: Dra. Polliana Muniz Alves. Programa de PósGraduação em Patologia Oral/Faculdade de Odontologia/UFRN. Av. Salgado Filho 1787, Lagoa Nova, 59056-000 Natal, RN.

Tel: 55 84 3215-4138/3215-4108.

e-mail: polliannaalves@ig.com.br

Recebido para publicação em 08/02/2008

Aceito em 06/03/2009
}

Sylvestris) apresenta propriedades diuréticas e expectorantes, podendo também ser utilizada no tratamento de inflamações das mucosas ${ }^{4}$. A aroeira-do-sertão (Myracrodruon urundeuva All) possui crescente uso farmacológico, pois na sua entrecasca são constatados a presença de Urundeuva A, Urundeuva B e taninos ${ }^{1}$. A Psidium guajava Linn (goiabeira) é bastante utilizada em casos de diarréia, mas possui também atividade antimicrobiana, antifúngica e antitussígen $a^{10}$. Assim sendo, o propósito deste estudo foi verificar in vitro a atividade antimicrobiana, antiaderente e antifúngica dos extratos vegetais da malva, aroeira-do-sertão e da goiabeira, na prevenção de formação do biofilme dental e proliferação de cepas do gênero Candida.

A matéria prima (folha da goiabeira e da malva, e casca do caule da aroeira-do-sertão) foi obtida em mercado público, e identificada botanicamente no Laboratório de Toxicologia. Posteriormente, foram separados os materiais e levados à secagem em estufa $\mathrm{a} 33^{\circ} \mathrm{C}$, durante uma semana, para eliminação de umidade e estabilização do conteúdo enzimático. Em seguida, o material foi triturado e submetido à extração dos princípios ativos, através da lixiviação. Utilizou-se linhagens padronizadas de Streptococcus mutans, Streptococcus mitis, Streptococcus sanguis, Streptococcus sobrinus, Lactobacillus casei, Candida albicans, Candida tropicalis, Candida stelatoidea e Candida krusei.

A atividade antimicrobiana e antifúngica foram determinadas pelo método de difusão em meio sólido, proposta por Bauer, Kirbi, Sherris e Turck² para a determinação da concentração 
inibitória mínima (CIM). Foi considerada como CIM a menor concentração dos extratos que inibiu completamente 0 crescimento dos microrganismos, ou seja, presença do halo de inibição. A concentração inibitória mínima de aderência (CIMA) foi determinada utilizando-se o método proposto por Gebara, Zardetto e Mayer ${ }^{5}$. A concentração inibitória mínima de aderência foi definida como a menor concentração do extrato que impediu a aderência bacteriana ao tubo de vidro. Todos os extratos foram diluídos em concentrações crescentes até 1: 512. Os mesmos procedimentos foram realizados com o gluconato de clorexidina a $0,12 \%$ (controle positivo), bem como com uma solução hidroalcóolica a 80\% (controle negativo).

Em relação aos resultados da concentração inibitória mínima, observou-se que todas as linhagens demonstraram serem sensiveis aos extratos hidroalcoólicos analisados, conforme mostra a Tabela $\mathbf{1 .}$ Quanto ao extrato da aroeira-do-sertão, o Lactobacillus casei foi o mais sensível. Fato de grande importância, pois se sabe que este é o microrganismo responsável pela consolidação e aumento da consistência do biofilme. E quando associado ao Streptococcus mutans contribui no processo de formação da cárie dentária ${ }^{11}$.

Na Tabela 1, também se observa que o Streptococcus mutans foi o mais sensível ao extrato da Psidium guajava Linn. Com relação ao extrato da malva, observou-se que o Streptococcus mutans e o Streptococcus sobrinus foram os mais sensíveis. Dados esses de grande importância, pois se sabe que a espécie Streptococcus mutans é encontrada em mais de $80 \%$ dos indivíduos, e que o Streptococcus sobrinus exibe uma maior cariogenicidade em superfícies lisas devido à maior produção de glucanos insolúveis 5 .

\section{TABELA 1}

Concentração inibitória mínima da aroeira-do-sertão, malva e goiabeira sobre as linhagens bacterianas.

\begin{tabular}{lccc}
\hline & \multicolumn{3}{c}{ Extratos analisados concentração do extrato $(\mathrm{mg} / \mathrm{ml})$} \\
\cline { 2 - 4 } Linhagens bacterianas & aroeira-do-sertão & malva & goiabeira \\
\hline Streptococcus mutans & $1: 8$ & $1: 4$ & $1: 32$ \\
Streptococcus mitis & $1: 4$ & EP & $1: 4$ \\
Streptococcus sobrinus & $1: 4$ & $1: 4$ & $1: 16$ \\
Streptococcus sanguis & $1: 8$ & $1: 2$ & $1: 4$ \\
Lactobacillus case $i$ & $1: 32$ & EP & $1: 16$ \\
\hline
\end{tabular}

EP: extrato puro

A Tabela 2 mostra que os três extratos apresentaram atividade antiaderente. Atividade esta representada pela ausência de aderência da bactéria a parede do tubo de vidro, demonstrando a capacidade dos extratos de inibir a síntese do glucano pela glicosiltransferase. Estes resultados obtidos são bastante promissores uma vez que os microrganismos analisados são os maiores responsáveis pela formação do biofilme dental.

Gebara, Zardetto e Mayer ${ }^{5}$ observaram ausência de atividade antimicrobiana e antiaderente da malva. Diferentemente dos nossos resultados, onde a malva além de exercer atividade antimicrobiana, mostrou-se também efetivo na inibição da síntese de glucanos, sobre todos os microrganismos analisados.

$\mathrm{Na}$ avaliação da atividade antifúngica observou-se que 0 extrato da aroeira-do-sertão apresentou atividade antifúngica sobre as cepas de Candida albicans, Candida tropicalis $\boldsymbol{e}$ Candida krusei (Tabela 3). Estes resultados são de grande valia, pois a Candida albicans e Candida krusei, entre outras

TABELA 2

Dados comparativos da concentração inibitória mínima de aderência dos extratos da aroeira-do-sertão, goiabeira, malva e do gluconato de clorexidina a $0,12 \%$ sobre as linhagens bacterianas.

\begin{tabular}{lccccc}
\hline Linhagens bacterianas & Aroeira do sertão & Malva & Goiabeira & $\begin{array}{c}\text { Clorexidina } \\
\text { (controle negativo) }\end{array}$ & $\begin{array}{c}\text { Solução } \\
\text { hidroalcóolica }\end{array}$ \\
\hline Streptococcus mutans & $1: 16$ & $1: 16$ & $1: 4$ & $1: 16$ & 0 \\
Streptococcus mitis & $1: 4$ & $1: 2$ & $1: 16$ & $1: 16$ & 0 \\
Streptococcus sobrimus & $1: 4$ & $1: 16$ & $1: 16$ & $1: 16$ & 0 \\
Streptoccoccus sanguis & $1: 4$ & $1: 16$ & $1: 8$ & $1: 16$ & 0 \\
Lactobacillus casei & $1: 16$ & $1: 16$ & $1: 16$ & $1: 16$ & 0 \\
\hline
\end{tabular}

\section{TABELA 3}

Concentração inibitória mínima do extrato da aroeira-do-sertão, malva e goiabeira sobre Candida albicans, Candida tropicalis, Candida stelatoidea e Candida krusei.

\begin{tabular}{lccc}
\hline \multirow{2}{*}{ Espécies fúngicas } & \multicolumn{3}{c}{ Extratos analisados concentração do extrato $(\mathrm{mg} / \mathrm{ml})$} \\
\cline { 2 - 4 } & aroeira-do-sertão & malva & goiabeira \\
\hline Candida albicans & $1: 8$ & $1: 2$ & $1: 32$ \\
Candida tropicalis & $1: 16$ & $1: 4$ & $1: 32$ \\
Candida stelatoidea & 0 & $1: 2$ & $1: 2$ \\
Candida krusei & $1: 16$ & $1: 2$ & $1: 2$ \\
\hline
\end{tabular}

EP: extrato puro espécies, têm sido detectadas como patogênicas nos casos de candidose bucal, principalmente naqueles relacionados à imunossupressão $0^{9}$. A malva e a goiabeira apresentaram atividade antifúngica sobre as quatro cepas de Candida analisadas (Tabela 3), semelhantemente aos resultados encontrados por Cárceres, Fletes e Aguilar ${ }^{3}$.

Neste sentido, os resultados obtidos mostram ser de grande valia a realização de pesquisas in vivo, para que desta forma, os extratos da aroeira-do-sertão, goiabeira e malva possam ser utilizadas, clinicamente, no tratamento da candidose oral e na prevenção de formação do biofilme dental. Concluindo, os 
resultados obtidos neste estudo mostram aimportância das indicações terapêuticas das plantas medicinais como método alternativo e de baixo custo, à nível de produção, na clínica odontológica, uma vez que os extratos hidroalcóolicos da aroeira-do-sertão, goiabeira e malva apresentaram in vitro potencial atividade antimicrobiana $\mathrm{e}$ antiaderente sobre os microrganismos formadores no biofilme dental, como também demonstraram atividade antifúngica sobre cepas de Candida isoladas da cavidade oral.

\section{REFERÊNCIAS}

1. Bandeira MAM. Identificação de chalconas diméricas nos brotos e renovos de aroeira-do-sertão (Myracrodruon urundeuva All.). In: Anais do XVI Simpósio de plantas medicinais do Brasil. Recife, p.193, 2000.

2. Bauer AW, Kirbi WMM, Sherris JC, Turck M. Antibiotic susceptibility testing by a standardized single disk method. American Journal Clinical Pathology 45: 493496, 1969 .

3. Cárceres A. Plants used in guatemala for the treatment of gastrointestinal disorders. 3. Confirmation of activity against enterobacterial plants. Journal Ethnopharmacology 38: 31-38, 1993.
4. Cardoso MLC. Malva sylvestris Linn. Revista Plantas em Destaque 8: 50, 1998.

5. Gebara ECE, Zardetto CGDC, Mayer MPA. Estudo in vitro da ação antimicrobiana de substâncias naturais sobre $S$. mutans e $S$. sobrinus. Revista Odontológica Universitária 10: 251-256, 1996.

6. Jardim Júnior EG, Pedrini D, Xavier EA, Jardim PS. Eficácia do listerine sobre a placa. Revista Gaúcha Odontológica 46: 70-78, 1998.

7. Machado WAS, Sardenberg SEM, Kahn S, Alves J. A clorexidina no controle de placa em pacientes internados: estudo piloto. Revista Brasileira Odontológica 59: 390-392, 2002

8. Pereira CV. Ação de amostras de Streptococcus mutans e Streptococcus sobrinus sobre diferentes carboidratos com ênfase dentária - estudo in vitro. Revista Passo Fundo 4: 33-39, 1999.

9. Ramos IC, Vasconcelos LS, Lima MC, Figueiredo RQ. Candidose Bucal em pacientes HIV-positivos. Jornal Brasileiro de Clínica 3: 59-61, 1999.

10. Santos FA, Cunha GMA, Viana GSB. Antibacterial activity of essencial oils from Psidium and Pilocarpus species of plants. Phytoterapy Research 12: 24-27, 1998.

11. Thylstrup A, Fejerskov 0. Cariologia clínica. Santos, SP, 1995.

12. Yanagida A. Inhibitory effects of apple polyphenols and related compounds on cariogenic factors of mutans streptococci. Journal Agricola Food Chemical 48: 5666-5671, 2000. 